\title{
Do reimbursement recommendation processes used by government drug plans in Canada adhere to good governance principles?
}

This article was published in the following Dove Press journal:

ClinicoEconomics and Outcomes Research

Number of times this article has been viewed

\author{
Nigel SB Rawson ${ }^{1-3}$ \\ John Adams ${ }^{4}$
}

'Eastlake Research Group, Oakville, ON, ${ }^{2}$ Canadian Health Policy Institute, Toronto, ON, ${ }^{3}$ Fraser Institute, Vancouver, BC, ${ }^{4}$ Canadian PKU and Allied Disorders Inc., Toronto, ON, Canada

Correspondence: Nigel SB Rawson Eastlake Research Group, Oakville, ON, Canada

Email EastlakeRG@gmail.com

\begin{abstract}
In democratic societies, good governance is the key to assuring the confidence of stakeholders and other citizens in how governments and organizations interact with and relate to them and how decisions are taken. Although defining good governance can be debatable, the United Nations Development Program (UNDP) set of principles is commonly used. The reimbursement recommendation processes of the Canadian Agency for Drugs and Technologies in Health (CADTH), which carries out assessments for all public drug plans outside Quebec, are examined in the light of the UNDP governance principles and compared with the National Institute for Health and Care Excellence system in England. The adherence of CADTH's processes to the principles of accountability, transparency, participatory, equity, responsiveness and consensus is poor, especially when compared with the English system, due in part to CADTH's lack of genuine independence. CADTH's overriding responsibility is toward the governments that "own," fund and manage it, while the agency's status as a not-for-profit corporation under federal law protects it from standard government forms of accountability. The recent integration of CADTH's reimbursement recommendation processes with the provincial public drug plans' collective system for price negotiation with pharmaceutical companies reinforces CADTH's role as a nonindependent partner in the pursuit of governments' cost-containment objectives, which should not be part of its function. Canadians need a national organization for evaluating drugs for reimbursement in the public interest that fully embraces the principles of good governance - one that is publicly accountable, transparent and fair and includes all stakeholders throughout its processes.
\end{abstract}

Keywords: drug reimbursement recommendation, health technology assessment, governance, Canada, drug insurance

\section{Plain language summary}

Good governance promotes the confidence of citizens in how governments and organizations interact with them and how decisions are made that impact them. The process that leads to a recommendation for coverage in drug insurance plans should be no exception. We examined how the drug reimbursement recommendation processes of the Canadian Agency for Drugs and Technologies in Health adhere to good governance principles. We found that their compliance with the principles of accountability, transparency, participatory, equity, responsiveness and consensus is poor, especially when compared with the system used in England. Canadians need a national organization for evaluating drugs for reimbursement in the public interest that fully embraces the principles of good governance - one that is publicly accountable, transparent and fair and includes all stakeholders throughout its processes. 


\section{Introduction}

In democratic societies, good governance should play a key role in how organizations interact with and relate to stakeholders and how decisions are taken. The Ottawa-based Institute on Governance defines governance as a process that "determines who has power, who makes decisions, how other players make their voice heard and how account is rendered." Since a process is difficult to observe, evaluations of governance focus on the framework upon which the process rests, ie, the policies that define who gets power, how decisions are taken and how accountability is safeguarded. The United Nations Development Program (UNDP) principles, which can be grouped into five themes (Table 1), are commonly used to describe good governance. ${ }^{2}$

All processes through which societies, governments and organizations make important decisions should adhere to these principles to inspire stakeholders' and public confidence in the processes and results. As health insurers contend with unmet health needs and increasing numbers of therapeutic drugs and their costs, they look to health technology assessment (HTA) to assist them with estimating the value of new medications. Drug reimbursement recommendation processes based on HTAs should comply with good governance principles to assure stakeholders, especially patients and their families, that recommendations are based on best available evidence of a drug's benefit, safety and cost, not cost-containment objectives alone.

The processes for recommending drugs for reimbursement in Canadian public drug plans are examined in the light of the UNDP governance principles. Although no universally agreed governance criteria exist, the UNDP principles were used because they are easily understood and used by the Institute on Governance and the World Health Organization. ${ }^{1,3}$ The examination is especially relevant following the release by the Canadian Agency for Drugs and Technologies in Health (CADTH) in 2017 of updated Guidelines for the Economic Evaluation of Health Technologies that, unlike previous versions, takes a "social decision-making viewpoint."

\section{Drug reimbursement recommendation processes in Canada}

Canada is the only country in the world with a universal government health insurance system for physicians, hospitalizations and laboratory services that does not cover all prescription drugs for patients in the community. Reimbursement for drugs is available through federal, provincial and territorial government-funded plans and private insurance paid for by individuals or cost-shared with employers, unions or associations. Government plans, which offer a degree of coverage to about a third of the Canadian population, are mainly designed to provide drug insurance to seniors, social assistance recipients and some special groups, such as cancer patients, or when costs are deemed to be catastrophic. However, the government plans have a complex system of deductibles, copayments and premiums and, for many drugs, special or restricted access criteria or therapeutic substitution that results in variation in patient eligibility, out-of-pocket

Table I United Nations Development Program principles of good governance

Accountability

- Accountability: decision-makers in government, the private sector and civil society organizations are accountable to the public and institutional stakeholders.

- Transparency: processes, institutions and information are directly accessible to those concerned with them and enough information is provided to understand and monitor them.

Fairness

- Equity: everyone has opportunities to improve or maintain their well-being.

- Rule of law: legal frameworks should be fair and enforced impartially.

Legitimacy and voice

- Participation: everyone should have a voice in decision-making either directly or through legitimate intermediate institutions that represent their interests.

- Consensus orientation: good governance mediates differing interests to reach a broad consensus on what is in the best interest of the group and, where possible, on policies and procedures.

Performance

- Responsiveness: institutions and processes try to serve all stakeholders.

- Effectiveness and efficiency: processes and institutions produce results that meet needs while making the best use of resources.

Direction

- Strategic vision: leaders and the public have a broad and long-term perspective on good governance and development, together with a sense of what is needed for such development and an understanding of the historical, cultural and social complexities on which the perspective is based.

Note: Adapted with permission from the Institute on Governance. Defining governance, 2003.' 
expenses and coverage, which has led to significant inequalities within and between provinces and territories. ${ }^{5-10}$

Although not a legal requirement, most drugs are evaluated by CADTH for payment/reimbursement recommendation for coverage within all federal, provincial and territorial public plans, except those in Quebec which has its own HTA agency. CADTH began life in 1989 as a pilot project known as the Canadian Coordinating Office for Health Technology Assessment with a focus on medical devices. Over the succeeding years, permanent funding was obtained and the organization's role expanded to include drugs. Its name changed to CADTH in 2006. CADTH is established as a not-for-profit corporation under federal law with 13 directors forming its Board. Currently chaired by an academic who has held senior roles within the Government of Ontario, the Board comprises four types of directors: "jurisdictional" (seven individuals holding Deputy Minister, Assistant Deputy Minister or Chief Clinical Advisor positions in federal, provincial or territorial governments of which six are directly responsible for drug plans), "health authorities" (a provincial health network administrator and a practising physician), "academic" (an individual with a relationship with the Government of British Columbia) and "public" (two individuals who are members of various companies and institutional boards). ${ }^{11}$ Thus, more than three-quarters of CADTH's Board members are employed by or directly associated with federal, provincial or territorial governments.

CADTH's role is to deliver "evidence, analysis, advice and recommendations to health care decision-makers so that they can make informed decisions." ${ }^{12}$ To pursue its role in drug reimbursement recommendations, CADTH has two processes: the pan-Canadian Oncology Drug Review (pCODR), ${ }^{13}$ which assesses oncology therapies, and the Common Drug Review (CDR) ${ }^{14}$ which evaluates all other drugs. Each review process has an expert committee - the pCODR Expert Review Committee (pERC) and the Canadian Drug Expert Committee (CDEC) - that provides non-binding reimbursement recommendations to participating drug plans. The $\mathrm{pERC}$ has 16 members of which three are patient representatives, ${ }^{15}$ while the $\mathrm{CDEC}$ has 12 academics and two members of the public for "a lay perspective," 16 but no patient members. Meetings of the pERC and CDEC are not open to patients, pharmaceutical manufacturers, the public or the media and proceedings are not accessible.

At around $80 \%,{ }^{17,18}$ the pERC positive reimbursement recommendation rate is significantly higher than the CDEC rate of 50-55\%. ${ }^{19-21}$ The overall CDEC rate obscures significant variation between different drug types, with particularly low rates for central nervous system, mental health and rare disorder drugs. ${ }^{19-22}$ Positive recommendations from both committees are commonly qualified with clinical criteria and/ or a need for a price reduction. CADTH does not publicly acknowledge having a cost-effectiveness ratio threshold for assessing drugs, but evidence exists to suggest that CAN\$50,000 per quality-adjusted life-year, first proposed in the early $1990 \mathrm{~s},{ }^{23}$ is used although not consistently applied ${ }^{18,19}$ (a higher threshold appears to be used where there are unmet therapeutic needs or a lack of alternative options and for rare disorder and oncology drugs). Negative recommendations are frequently based on the expert committee's opinion that a drug's efficacy evidence is inadequate ${ }^{19,24}$ despite having been assessed by Health Canada's regulatory review as acceptable. While regulatory and HTA reviews have different objectives, ${ }^{25}$ this can result in CADTH's committees duplicating work already done by the federal agency.

CADTH describes itself as "an independent, not-forprofit organization responsible for providing Canada's health care decision-makers with objective evidence to help make informed decisions about the optimal use of drugs." 26 CADTH documentation also states that the agency, in its own words, "is owned by, and reports directly to, the 13 provincial and territorial Deputy Ministers of Health and the federal Deputy Minister of Health." ${ }^{27}$ The health ministries provide $85 \%$ of CADTH's annual operating budget of approximately CAN\$28 million. ${ }^{28}$ Thus, CADTH's activities are dominated by its allegiance to the governments that own and control it through funding and board member appointments.

Partiality toward its funders was demonstrated in early 2015 when provincial governments requested CADTH to conduct a therapeutic review (an assessment of data regarding a therapeutic category to support listing and policy decisions and encourage optimal therapy) of the use of bevacizumab (Avastin ${ }^{\circledR}$; Roche Holding AG, Basel, Switzerland), ranibizumab (Lucentis ${ }^{\circledR}$; Novartis, Basel, Switzerland) and aflibercept (Eylea ${ }^{\circledR}$; Bayer, Leverkusen, Germany) for retinal conditions. ${ }^{29} \mathrm{Up}$ to this point, therapeutic reviews had been performed to provide recommendations at the time of a new drug submission to CADTH. However, without consultation, CADTH changed its rules to allow a review to be done at any time and to extend the scope to include "evidence-based expanded use (ie, for a clinical indication not included in an approved Health Canada product monograph)." ${ }^{30}$ This change in its rules allowed CADTH to include bevacizumab, which is not approved for retinal conditions and has a serious Health Canada warning stating that it is not authorized for such use, in its therapeutic review. Moreover, CADTH excluded evidence from observational studies that suggested increased safety risks with bevacizumab. These circumstances predis- 
posed the conclusion that bevacizumab and ranibizumab have similar efficacy and safety profiles. This justified the recommendation that bevacizumab, at a fraction of the price of ranibizumab, should be used off-label as the preferred initial therapy for retinal conditions. ${ }^{31}$ While the safety risks of intravitreal bevacizumab have yet to be resolved, CADTH's change in its rules for therapeutic reviews led to a positive recommendation for off-label use of bevacizumab contrary to Health Canada's regulatory approval for the drug that allows government drug plans to reduce costs.

\section{Price negotiations for coverage in Canadian public drug plans}

Unlike many other countries, Canada does not have a national purchasing authority that uses the state's bulk-buying power to negotiate lower drug prices. Instead, it has a complex network of multiple, overlapping federal, provincial, territorial and private sector organizations, arrangements and initiatives directed at containing, if not controlling, expenditure.

Since the late 1980s, the Patented Medicine Prices Review Board (PMPRB), an independent quasi-judicial body established under Canada's "Patent Act" carrying out its mandate at arms-length from the federal Minister of Health, has had the primary role in ensuring that prices for patented medicines are not excessive. ${ }^{32}$ The PMPRB compares the price that a company proposes to charge for a new drug in Canada with prices in seven comparator countries - France, Germany, Italy, Sweden, Switzerland, the United Kingdom and the United States - and sets a ceiling price based on uniqueness of the product and the Board's assessment of the drug's therapeutic benefit.

Drug expenditures have, nevertheless, been increasing and the PMPRB has been criticized as being "cautious" about calling out "suboptimal purchasing and pricing." 33 The PMPRB is presently under review with the aim of reforming its processes. ${ }^{34}$ In August 2010, provincial and territorial governments, with the exception of Quebec, established their own process, known as the pan-Canadian Pharmaceutical Alliance (pCPA), to negotiate prices of new drugs with pharmaceutical companies. ${ }^{35}$ Development of the process took several years such that the pCPA only became a formalized entity with a permanent government-funded staff and office in 2015. In 2016, the Quebec and federal government drug plans joined the pCPA.

By capitalizing on the combined governments' buying power, the pCPA's objectives are to increase access to drug options, achieve lower drug costs and consistent pricing, and improve consistency of coverage criteria across Canada. The cost-containment objective is demonstrated by the pCPA's submission to the PMPRB's reform consultation process in which it recommended that the United States be replaced as a comparator by New Zealand, Australia, South Korea or Brazil, ${ }^{36}$ where drug prices are strictly contained. New Zealand's cost-containment model has been promoted by academics as one that Canada should emulate, ${ }^{37,38}$ despite New Zealand providing fewer therapeutic options and having higher mortality rates for some serious conditions than Canada. ${ }^{39}$

Since May 2016, pCPA representatives are included in CADTH processes to provide an opportunity for the pCPA "to receive relevant information on drugs reviewed through the CDR and pCODR processes" and to "support business planning." ${ }^{40}$ The pCPA is an observer in meetings of CDEC, $\mathrm{pERC}$ and their advisory groups and receives confidential and redacted information from the recommendation processes (Table 2). Thus, CADTH and pCPA are now closely interconnected.

A 2017 analysis of recommendations for rare disorder drugs indicates that an objective of the CADTH-pCPA integration is to ensure that a negative recommendation results in no pCPA negotiation, while a positive one sets up factors for inclusion in the negotiation (usually the need for a price reduction) between the pCPA and pharmaceutical manufacturer. ${ }^{24}$ The analysis further demonstrated that a drug's cost is associated with the likelihood of a negative CDR recommendation; for drugs used daily that had an estimated annual cost of less than CAN\$55,000, the negative recommendation rate was $17 \%$, compared with a rate of $74 \%$ for drugs costing more than CAN\$55,000. ${ }^{41}$

\section{Drug reimbursement recommendation process in England}

In England, the assessment of drugs for reimbursement is performed for the publicly funded National Health System (NHS) by the National Institute for Health and Care Excellence (NICE), which describes its processes in greater detail on its website than CADTH does. ${ }^{42}$ NICE was originally created in 1999 as a special health authority with a focus on reducing variation in the availability and quality of NHS treatments and care. It was formally established as a Non-Departmental Public Body in the 2012 "Health and Social Care Act."

NICE is led by a Board of 16 members: nine "nonexecutive directors" (currently three physicians, a nurse, two health policy researchers, a life sciences executive, a health charity chief executive and the chairperson of an NHS audit 
Table 2 Integration of the CADTH processes and the pan-Canadian Pharmaceutical Alliance

\begin{tabular}{|c|c|c|c|}
\hline $\begin{array}{l}\text { CADTH process or } \\
\text { meeting }\end{array}$ & Pan-Canadian Pharmaceutical Alliance & $\begin{array}{l}\text { Pharmaceutical } \\
\text { manufacturers }\end{array}$ & Patient groups \\
\hline Pre-submission meetings & Observer; may ask clarification questions & No attendance & No attendance \\
\hline CDR process & $\begin{array}{l}\text { Receives drug submission information } \\
\text { including confidential, nondisclosable or } \\
\text { redacted information }\end{array}$ & Drug submission for review & $\begin{array}{l}\text { Submission about disease impact, } \\
\text { current therapy effectiveness and } \\
\text { expectations for new drug }\end{array}$ \\
\hline PCODR process & $\begin{array}{l}\text { Receives drug submission information } \\
\text { including confidential, nondisclosable or } \\
\text { redacted information }\end{array}$ & Drug submission for review & $\begin{array}{l}\text { Submission about disease impact, } \\
\text { current therapy effectiveness and } \\
\text { expectations for new drug }\end{array}$ \\
\hline $\begin{array}{l}\text { Canadian Drug Expert } \\
\text { Committee meeting }^{\mathrm{a}}\end{array}$ & Observer & $\begin{array}{l}\text { No attendance; may } \\
\text { comment on draft } \\
\text { recommendation }\end{array}$ & $\begin{array}{l}\text { No attendance; do not receive } \\
\text { draft recommendation }\end{array}$ \\
\hline $\begin{array}{l}\text { PCODR Expert Review } \\
\text { Committee meeting }\end{array}$ & Observer & $\begin{array}{l}\text { No attendance; may } \\
\text { comment on draft } \\
\text { recommendation }\end{array}$ & $\begin{array}{l}\text { Representatives attend; } \\
\text { may comment on draft } \\
\text { recommendation }\end{array}$ \\
\hline $\begin{array}{l}\text { Drug Policy Advisory } \\
\text { Committee-Formulary } \\
\text { Working Group }{ }^{\mathrm{b}} \text { meeting }\end{array}$ & $\begin{array}{l}\text { Observer; may provide updates or contribute } \\
\text { to potential drug recommendation } \\
\text { implementation issues that fit within scope of } \\
\text { CDR reviews }\end{array}$ & No attendance & No attendance \\
\hline $\begin{array}{l}\text { pCODR Expert Review } \\
\text { Committee-Provincial Advisory } \\
\text { Group }{ }^{c} \text { meeting }\end{array}$ & $\begin{array}{l}\text { Observer; may provide updates or contribute } \\
\text { to potential drug recommendation } \\
\text { implementation issues that fit within scope of } \\
\text { pCODR reviews }\end{array}$ & No attendance & No attendance \\
\hline
\end{tabular}

Notes: anput regarding potential recommendation implementation issues that fit within the scope of the CDR provided by participating drug plan members and panCanadian Pharmaceutical Alliance representatives is taken into consideration at these meetings ${ }^{40}$; bincludes representatives from federal, provincial and territorial public drug plans and other related health organizations who provide advice on pharmaceutical issues related to the CDR process ${ }^{43}$; ${ }^{c} p r o v i d e s$ advice about operational issues and strategic and policy direction. ${ }^{44}$

Abbreviations: CADTH, Canadian Agency for Drugs and Technologies in Health; CDR, Common Drug Review; pCODR, pan-Canadian Oncology Drug Review.

committee), four "executive directors" (chief executive, deputy chief executive, director of business planning and resources, and director of HTA at NICE) and three "directors" responsible for NICE clinical guidelines, communications, and information management and technology. ${ }^{45}$ Two nonexecutive directors are the Board's chair and vice-chair.

NICE's core principles, which are listed in its publicly available charter, ${ }^{46}$ include public involvement, independence, consultation, transparency, equity and social value. How NICE makes social value judgments is detailed in a separate document. ${ }^{47}$ To help it understand the public's views and incorporate them into decision-making, NICE has an advisory Citizens Council made up of members of the public from across the United Kingdom. ${ }^{48}$

NICE reviews all new oncology and most other new drugs for reimbursement coverage, although there is no formal requirement for non-oncology drugs to be evaluated. NICE's positive recommendation rate is reported to be $76 \% .{ }^{21}$ The NHS has been obligated to provide funding for drugs recommended by NICE since January 2005, but the implementation of recommendations has been shown to be uneven across the NHS. ${ }^{49}$ A negative recommendation normally excludes a drug from reimbursement.
Drug reimbursement recommendation assessment is performed by an Appraisal Committee whose membership includes representatives from the NHS, academia and the pharmaceutical industry and individuals "with an understanding of patient and public perspectives on health care issues." ${ }^{50}$ NICE also invites "consultees" to take part in the review that include national groups representing patients and caregivers, health care professional organizations, the drug's manufacturer and government representatives, ${ }^{49}$ since "patients and public involvement has always been a requirement" in its assessment process. ${ }^{51}$

Appraisal Committee meetings are open to patients, pharmaceutical manufacturers, members of the public and the media, unless confidential or commercially sensitive information (eg, unpublished study results) is being discussed, as part of NICE's commitment to openness and transparency to enable "stakeholders and the public to understand how evidence is assessed and interpreted and how consultation comments are taken into account." ${ }^{52}$ Preliminary recommendation reports are available to all stakeholders, each of which can respond with comments. Although representatives of the NHS attend Appraisal Committee meetings, government interference in NICE's affairs has been minimal. ${ }^{49}$ 
The different approach of NICE to that of CADTH is demonstrated by the result of a 2010 workshop held to consider whether an appraisal of bevacizumab for retinal conditions was appropriate. The conclusion was that, although support for an appraisal existed, it would need to be conditional on an assessment of the safety and quality of intravitreal bevacizumab by a regulatory body. ${ }^{53}$ The situation remains the same in 2017.

Another example of the variation between NICE and CADTH appears in their reviews of eculizumab (Soliris ${ }^{\circledR}$; Alexion Pharmaceuticals, New Haven, CT, USA) for atypical hemolytic uremic syndrome (aHUS), which is a chronic, rare, progressive condition causing severe inflammation of blood vessels and the formation of clots in small blood vessels placing sufferers at risk of progressive damage and failure of vital organs, especially the kidneys. NICE produced an extensive guidance report that demonstrates its openness and stakeholder inclusiveness. The report concluded that "eculizumab is a very effective treatment option for patients with aHUS" and that, despite the limitations of the company's economic model, "other benefits of a substantial nature had not been adequately captured in the model and, therefore, may have led to underestimation of the overall effectiveness of eculizumab. ${ }^{54}$ NICE acknowledged "the potential wider societal benefits of eculizumab" and recommended funding for eculizumab for aHUS subject to some appropriate conditions.

Reviewing the same clinical evidence, CADTH recommended that eculizumab not be listed because "the clinical benefit could not be adequately established" and the economic model had several limitations, including insufficient evidence of the "relative benefit of eculizumab in relation to plasma therapy" (current therapy which has limited effectiveness). ${ }^{55} \mathrm{~A}$ further analysis by CADTH in response to a request for advice from CDR-participating drug plans provided some criteria for the use of eculizumab for aHUS, but the recommendation remained negative. ${ }^{56}$ Although both agencies expressed considerable concern about the drug's high cost and its impact on the budgets of their respective health systems in their reviews, NICE took a more holistic perspective than $\mathrm{CADTH}$, which seemed to be more focused on eculizumab's "significant cost consequence" on drug plan budgets than individual or societal benefits.

\section{Governance of drug reimbursement recommendation processes in Canada and England}

The evaluation of a drug for consideration of reimbursement by public insurance schemes impacts several stakeholders: governments, manufacturers, health care professionals, the public and patients and their caregivers. Patients are taxpaying members of the public, who have a particular interest in accessing medications and, as such, are the stakeholders most vulnerable if access is delayed, restricted or denied.

Accountability and transparency are fundamental principles of good governance, which require a process to report, explain and answer for the consequences of decisions so that all stakeholders can see how and why they were taken. All stakeholders should also have an opportunity to improve their well-being by participating throughout the process and having a voice in decision-making. Good governance principles further demand that the process be responsive (by serving the needs of all involved), consensus building and equitable with all stakeholders, particularly the most vulnerable, being assured that their interests are considered in the decisionmaking process. The principles of good governance should be incorporated into reimbursement recommendation processes.

NICE is held accountable by an Act of Parliament, but CADTH is not similarly answerable. Information regarding NICE's governance and accountability is publicly available. ${ }^{57}$ NICE is subject to public and parliamentary accountability including a code of conduct for Board and staff members containing rules on financial and other conflicts of interest, freedom of information requests, a whistle-blower policy and audit requirements. In contrast, CADTH's governance documentation is not publicly available and CADTH is protected from freedom of information requests, whistle-blowing, Auditor General of Canada reviews and ombudsman or integrity commissioner inquiries and investigations.

NICE meetings are open and all stakeholders, including pharmaceutical companies, patients and the media, have access to all information and discussions related to a drug's review. In Canada, pharmaceutical manufacturers can comment on draft CDEC and pERC recommendations but cannot participate in discussions. Although cognizant of its own redacted confidential data, a manufacturer is denied access to other confidential information discussed at CDEC or pERC meetings, which is shared with pCPA observers at these meetings prior to governments deciding whether and how price negotiations will proceed. Consequently, the pCPA has a significant advantage if negotiations are opened. Anecdotal evidence from pharmaceutical professionals engaged in negotiations suggests that the pCPA uses the information it gains to decide on what price reduction it wants or why the company's position is unacceptable, while remaining uncompromising about its own objectives.

As the most vulnerable, patients are the stakeholders that should receive priority engagement in drug reimbursement 
recommendation processes. ${ }^{58}$ Patient groups can make written submissions in the CADTH processes regarding the impact of the condition for which a drug is indicated, effectiveness of present treatments and their expectations for a new therapy. Producing an effective, rather than an emotional, submission is challenging for small patient groups with limited resources. ${ }^{59}$ NICE has a public involvement program with a team of 13 fulltime equivalent staff to support such submissions, ${ }^{60}$ whereas CADTH has three staff members to provide support to patient groups, resulting in submission support and feedback being extremely limited and creating dissatisfaction. ${ }^{59}$

Patient representatives participate in pERC meetings, and draft reports are shared with all stakeholders including patient groups. CDEC meetings exclude patients, and draft reports are only shared with the relevant manufacturer. Patient groups can comment only on the CDR summary of their written submission included in the draft recommendation report, raising uncertainty about how much weight is given to patient input. ${ }^{59}$ The pCODR process complies with transparency and participatory governance principles with regard to patients to a greater extent than the CDR process, but both fail in accountability and equity principles. Although CADTH invites patient groups to its annual symposium and irregularly scheduled meetings of a Patient Liaison Forum, they are no substitute for real participation in the recommendation processes.

\section{Limitations}

Since objective criteria for evaluating whether an organization satisfies the good governance principles do not exist, this assessment inevitably has a degree of subjectivity. However, we have included evidence to substantiate our perspective. Some may consider that the CADTH-pCPA relationship means that an evaluation of CADTH alone is insufficient. The lack of public information about the policies, processes, practices and governance of the pCPA $^{61,62}$ (other than it is only accountable to the federal, provincial and territorial governments) makes an assessment of its governance difficult. Nevertheless, it is clear that the pCPA does not meet the transparency governance principle and fails the participatory principle because patients have no opportunity to engage in negotiations or even in the formulation of the objectives and framework for negotiations.

\section{Conclusion}

The history of the review of drugs for government reimbursement in Canada has been one of inconsistent decision-making and a lack of transparency and accountability to patients and the public, resulting in discriminatory access to new medications as many analyses have demonstrated..$^{5-9,63-67}$ In part, this is due to the complexity of the drug reimbursement systems in Canada which, unlike many European countries, lack universality, comprehensiveness and fairness; have siloed prescription drug budgets that are not fully integrated with other components of the health system; and may be influenced by political considerations. ${ }^{68}$ To some extent, it is also the result of HTA in Canada, like that in other countries, ${ }^{69}$ being an unstandardized deliberative evaluation based mainly on information derived from randomized clinical trials and drug prices higher than those offered to or negotiated by large insurers, which results in an assessment that is not necessarily indicative of the drug's value when used in everyday clinical practice.

No system of assessing the value of new drugs that limits or denies patient access will ever satisfy all stakeholders, but good governance principles should apply to drug reimbursement recommendation processes. The adherence of CADTH's processes to the UNDP governance principles of accountability, transparency, participation, equity, responsiveness and consensus building is poor, due in part to its lack of genuine independence, and considerably worse than that of England's NICE. CADTH's overriding responsibility is toward the governments that own, fund, govern and manage the agency. Integrating CDR and pCODR processes with the pCPA results in the CADTH-pCPA combination being a nonindependent participant in the pursuit of governments' cost-containment objectives, which should not be part of CADTH's role.

Although it may not be merited, ${ }^{70}$ Canada has an international reputation for openness and fairness and is a member of the Right to Know Movement. ${ }^{71}$ Its federal government was elected in 2015 on a platform of openness, transparency and fairness ${ }^{72}$ and the Prime Minister frequently refers to his government as being open, accountable and fair. ${ }^{73,74}$ The federal, provincial and territorial governments of Canada should apply these values to HTAs to provide Canadians with a national organization for evaluating drugs for reimbursement that fully embraces the principles of good governance - one that is publicly accountable, transparent and fair and includes all stakeholders throughout its processes.

\section{Acknowledgment}

The authors gratefully acknowledge support for the publication processing fee from Canadian PKU and Allied Disorders Inc. Canadian PKU and Allied Disorders Inc. had no input into the concept, content or writing of the manuscript. No other funding for the development of this work was received from any source. 


\section{Disclosure}

The authors report no conflicts of interest in this work.

\section{References}

1. Defining governance. Ottawa: Institute on Governance; 2003. Available from: https://iog.ca/docs/2003_August_policybrief15.pdf. Accessed October 15, 2017.

2. Governance for sustainable human development: a UNDP policy document. New York: United Nations Development Program; 1997. Available from: http://www.pogar.org/publications/other/undp/governance/ undppolicydoc97-e.pdf. Accessed October 15, 2017.

3. Stewardship/governance of health systems in the WHO European Region. EUR/RC58/9. 28. Copenhagen: WHO Regional Office for Europe; 2008. Available from: http://www.euro.who.int/_data/assets/ pdf_file/0016/70180/RC58_edoc09.pdf. Accessed October 15, 2017.

4. Guidelines for the Economic Evaluation of Health Technologies: Canada. Ottawa: Canadian Agency for Drugs and Technologies in Health; 2017. Available from: https://www.cadth.ca/guidelines-economic-evaluation-health-technologies-canada-4th-edition. Accessed October 15, 2017.

5. Anis AH, Guh D, Wang XH. A dog's breakfast: prescription drug coverage varies widely across Canada. Med Care. 2001;39(4):315-326.

6. West R, Borden EK, Collet JP, Rawson NSB, Tonks RS. "Costeffectiveness" estimates result in flawed decision-making in listing drugs for reimbursement. Can J Public Health. 2002;93(6):421-425.

7. Demers V, Melo M, Jackevicius C, et al. Comparison of provincial prescription drug plans and the impact on patients' annual drug expenditures. CMAJ. 2008;178(4):405-409.

8. LeLorier J, Bell A, Bougher DJ, Cox JL, Turpie AGG. Drug reimbursement policies in Canada: need for improved access to critical therapies. Ann Pharmacother. 2008;42(6):869-873.

9. Skinner BJ. Waiting for reimbursement of new medicines in Canada: it's time for a rethink. Pharmacoeconomics. 2008;26(8):629-632.

10. Rawson NSB. Drug Safety: Problems, Pitfalls and Solutions in Identifying and Evaluating Risk. Victoria, BC: FriesenPress; 2016.

11. Board of Directors. Ottawa: Canadian Agency for Drugs and Technologies in Health; 2017. Available from: https:/www.cadth.ca/about-cadth/ who-we-are/board-of-directors. Accessed October 15, 2017.

12. What we do. Ottawa: Canadian Agency for Drugs and Technologies in Health; 2017. Available from: https://www.cadth.ca/about-cadth/ what-we-do. Accessed October 15, 2017.

13. CADTH pan-Canadian Oncology Drug Review. Ottawa: Canadian Agency for Drugs and Technologies in Health; 2017. Available from: https://www.cadth.ca/pcodr. Accessed October 15, 2017.

14. CADTH Common Drug Review (CDR). Ottawa: Canadian Agency for Drugs and Technologies in Health; 2017. Available from: https:// www.cadth.ca/about-cadth/what-we-do/products-services/cdr. Accessed October 15, 2017.

15. The pCODR Expert Review Committee (pERC). Ottawa: Canadian Agency for Drugs and Technologies in Health; 2017. Available from: https://www.cadth.ca/collaboration-and-outreach/advisory-bodies/ pcodr-expert-review-committee-perc. Accessed October 15, 2017.

16. Canadian Drug Expert Committee (CDEC). Ottawa: Canadian Agency for Drugs and Technologies in Health; 2017. Available from: https:// www.cadth.ca/collaboration-and-outreach/advisory-bodies/canadiandrug-expert-committee-cdec. Accessed October 15, 2017.

17. Rawson NSB. Has pCODR improved access to oncology drugs? Timeliness and provincial acceptance of pan-Canadian Oncology Drug Review recommendations. Vancouver: Fraser Institute; 2014 June. Available from: https://www.fraserinstitute.org/sites/default/files/ has-pCODR-improved-access-to-oncology-drugs-rev.pdf. Accessed October 15, 2017.

18. Griffiths EA, Vadlamudi NK. CADTH's $\$ 50,000$ cost-effectiveness threshold: fact or fiction? Waltham, MA: Parexel International Corporation; 2016. Available from: https://www.ispor.org/research_pdfs/54/ pdffiles/PHP278.pdf. Accessed October 15, 2017.
19. Rocchi A, Miller E, Hopkins RB, Goeree R. Common Drug Review recommendations: an evidence base for expectations? Pharmacoeconomics. 2012;30(3):229-246.

20. Rawson NSB. Are the cost-effectiveness rules used by public drug plans denying coverage to Canadians with rare disorders? Canadian Health Policy. Toronto: Canadian Health Policy Institute; 2015. Available from: http://www.canadianhealthpolicy.com/products/are-cost-effectivenessrules-in-public-drug-plans-denying-coverage-to-canadians-with-raredisorders-.html. Accessed October 15, 2017.

21. Griffiths EA, Hendrich JK, Stoddart SDR, Walsh SCM. Acceptance of health technology assessment submissions with incremental costeffectiveness ratios above the cost-effectiveness threshold. Clinicoecon Outcomes Res. 2015;7:463-476.

22. Tran K, Rawson NSB, Skinner BJ. HTA decisions and access to mental health treatments in Canada's public drug plans. Canadian Health Policy. Toronto: Canadian Health Policy Institute; 2017. Available from: http://www.canadianhealthpolicy.com/products/hta-decisions-andaccess-to-mental-health-treatments-in-canada---s-public-drug-plans. html. Accessed October 15, 2017.

23. Grosse SD. Assessing cost-effectiveness in healthcare: history of the $\$ 50,000$ per QALY threshold. Expert Rev Pharmacoecon Outcomes Res. 2008;8(2):165-178.

24. Rawson NSB. Health technology assessment of new drugs for rare disorders in Canada: impact of disease prevalence and cost. Orphanet J Rare Dis. 2017;12(1):59.

25. Tsoi B, O’Reilly D, Masucci L, Drummond M, Goeree R. Harmonization of HTA-based reimbursement and regulatory approval activities: a qualitative study. J Popul Ther Clin Pharmacol. 2015;22(1):e78-89.

26. Who we are. Ottawa: Canadian Agency for Drugs and Technologies in Health; 2017. Available from: https://www.cadth.ca/about-cadth/whowe-are. Accessed October 15, 2017.

27. The Common Drug Review-myths versus facts. Ottawa: Canadian Agency for Drugs and Technologies in Health; 2017. Available from: https://www.cadth.ca/media/cdr/cdr-pdf/cdr_myths_facts_e.pdf. Accessed October 15, 2017.

28. O'Rourke B. Standing Committee on Health. Ottawa: Parliament of Canada; 2016. Available from: http://www.parl.gc.ca/HousePublications $/$ Publication. asp $x$ ? DocId $=8185563 \&$ Language $=E \&$ Mode $=1$. Accessed October 15, 2017.

29. Rawson NSB. Including off-label drug indications in HTA jeopardizes patient health and discourages innovation. Canadian Health Policy. Toronto: Canadian Health Policy Institute; 2016. Available from: http:// www.canadianhealthpolicy.com/products/including-off-label-drug-indications-in-hta-jeopardizes-patient-health-and-discourages-innovation. html. Accessed October 15, 2017.

30. Updates to the therapeutic review framework. Ottawa: Canadian Agency for Drugs and Technologies in Health; 2015. Available from: https://www.cadth.ca/updates-therapeutic-review-framework. Accessed October 15, 2017.

31. Anti-vascular endothelial growth factor drugs for the treatment of retinal conditions-recommendations report. Ottawa: Canadian Agency for Drugs and Technologies in Health; 2016. Available from: https://www. cadth.ca/sites/default/files/pdf/TR0009_Anti-VEGFs_Recs_Report. pdf. Accessed October 15, 2017.

32. About the PMPRB. Ottawa: Government of Canada; 2017. Available from: http://www.pmprb-cepmb.gc.ca/home. Accessed October 15, 2017.

33. Zhang R, Martin D, Naylor CD. Regulator or regulatory shield? The case for reforming Canada's Patented Medicine Prices Review Board. CMAJ. 2017;189(14):E515-16.

34. Protecting Canadians from excessive drug prices: consulting on proposed amendments to the patented medicines regulations. Ottawa: Government of Canada; 2017. Available from: https://www.canada.ca/en/ health-canada/programs/consultation-regulations-patented-medicine/ document.html. Accessed October 15, 2017.

35. The pan-Canadian Pharmaceutical Alliance. Ottawa: Council of the Federation Secretariat; 2013. Available from: http://www.pmprovincesterritoires.ca/en/initiatives/358-pan-canadian-pricing-alliance. Accessed October 15, 2017. 
36. Questions for discussion. Toronto: Pan-Canadian Pharmaceutical Alliance; 2016. Available from: http://www.pmprb-cepmb.gc.ca/CMFiles/ Consultations/Rethinking_the_Guidelines_2016/Submission_PCPA_ Oct_2016.pdf. Accessed October 15, 2017.

37. Morgan SG, Martin D, Gagnon MA, Mintzes B, Daw JR, Lexchin J. The future of drug coverage in Canada. Vancouver: University of British Columbia; 2015. http://pharmacare2020.ca/assets/pdf/The_Future_of_ Drug_Coverage_in_Canada.pdf. Accessed: October 15, 2017.

38. Morgan SG, Li W, Yau B, Persaud N. Estimating effects of adding universal public coverage of an essential medicines list to existing public drug plans in Canada. CMAJ. 2017;189(8):E295-E302.

39. Rawson NSB. Fewer treatment options for patients if Canada adopts New Zealand's prescription drug policies. Canadian Health Policy Toronto: Canadian Health Policy Institute; 2016. Available from: http:// www.canadianhealthpolicy.com/products/fewer-treatment-options-forpatients-if-canada-adopts-new-zealand--s-prescription-drug-policieshtml. Accessed October 15, 2017.

40. CDR Update - Issue 119. Ottawa: Canadian Agency for Drugs and Technologies in Health; 2016. Available from: https://www.cadth.ca/ cdr-update-issue-119. Accessed October 15, 2017.

41. Rawson NSB. Presentation at Healthy Canada Conference 2017: access to affordable medicines. Ottawa: Conference Board of Canada; 2017 Available from: http://www.conferenceboard.ca/Libraries/CONF_ PRES_PUBLIC/17-0064_p8_rawson.sflb. Accessed October 15, 2017.

42. Improving health and social care through evidence-based guidance. London: National Institute for Health and Care Excellence; 2017. Available from: https://www.nice.org.uk. Accessed October 15, 2017.

43. DPAC Formulary Working Group. Ottawa: Canadian Agency for Drugs and Technologies in Health; 2017. Available from: https://www.cadth.ca/ collaboration-and-outreach/advisory-bodies/dpac-formulary-workinggroup. Accessed October 15, 2017.

44. pCODR Provincial Advisory Group. Ottawa: Canadian Agency for Drugs and Technologies in Health; 2017. Available from: https://www. cadth.ca/collaboration-and-outreach/advisory-bodies/pcodr-provincialadvisory-group. Accessed October 15, 2017.

45. Board. London: National Institute for Health and Care Excellence; 2017. Available from: https://www.nice.org.uk/about/who-we-are/board. Accessed October 15, 2017.

46. NICE charter. London: National Institute for Health and Care Excellence; 2017. Available from: https://www.nice.org.uk/Media/Default/ About/Who-we-are/NICE_Charter.pdf. Accessed October 15, 2017.

47. Social value judgements: principles for the development of NICE guidance. 2nd ed. London: National Institute for Health and Care Excellence; 2017. Available from: https://www.nice.org.uk/Media/ Default/About/what-we-do/Research-and-development/Social-ValueJudgements-principles-for-the-development-of-NICE-guidance.pdf. Accessed October 15, 2017.

48. What are the societal values that need to be considered when making decisions about trade-offs between equity and efficiency? NICE Citizens Council Meeting Report; May 8-9, 2014. London: National Institute for Health and Care Excellence; 2017. Available from: https://www. nice.org.uk/Media/Default/Get-involved/Citizens-Council/Reports/ cc-report17-equity-efficiency.pdf. Accessed October 15, 2017.

49. Drummond M, Sorenson C. Nasty or nice? A perspective on the use of health technology assessment in the United Kingdom. Value Health. 2009;12(Suppl 2):S8-S13.

50. Fischer KE, Heisser T, Stargardt T. Health benefit assessment of pharmaceuticals: an international comparison of decisions from Germany, England, Scotland and Australia. Health Policy. 2016;120(10):1115-1122.

51. Raftery J, Powell J. Health technology assessment in the UK. Lancet. 2013;382(9900):1278-1285.

52. Guide to the processes of technology appraisal. London: National Institute for Health and Care Excellence; 2014. Available from: https://www. nice.org.uk/process/pmg19/chapter/the-appraisal-process. Accessed October 15, 2017.
53. Bevacizumab (Avastin) for eye conditions: report of findings from a workshop held at NICE on 13 July 2010. London: National Institute for Health and Care Excellence; 2010. Available from: https://www. nice.org.uk/Media/Default/About/what-we-do/NICE-guidance/NICEtechnology-appraisals/Proposed-appraisals-no-wave/bevacizumabexploratory-work-workshop-findings.pdf. Accessed: October 15, 2017.

54. Eculizumab for treating atypical hemolytic uremic syndrome: highly specialized technologies guidance. London: National Institute for Health and Care Excellence; 2015. Available from: https://www.nice.org.uk/ guidance/hst1/resources/eculizumab-for-treating-atypical-haemolyticuraemic-syndrome-pdf-1394895848389. Accessed October 15, 2017.

55. CDEC final recommendation, eculizumab (Soliris - Alexion Pharmaceuticals Inc.), new indication: atypical hemolytic uremic syndrome. Ottawa: Canadian Agency for Drugs and Technologies in Health; 2013. Available from: https://www.cadth.ca/sites/default/files/cdr/complete/ cdr_complete_Soliris-aHUS_July-23-13.pdf. Accessed October 15, 2017.

56. CDR request for advice report. Ottawa: Canadian Agency for Drugs and Technologies in Health; 2015. Available from: https://www.cadth ca/sites/default/files/cdr/advice/SF0416_Soliris_aHUS_RfA_Report. pdf. Accessed October 15, 2017.

57. Framework agreement between the Department of Health and the National Institute for Health and Care Excellence 2014. London: National Institute for Health and Care Excellence; 2014. Available from: https://www.nice.org.uk/Media/Default/about/who-we-are/ NICE-and-Dept-of-Health-Framework-Agreement-March-2014.pdf. Accessed October 15, 2017.

58. Wale J, Scott AM, Hofmann B, Garner S, Low E, Sansom L. Why patients should be involved in health technology assessment. Int $J$ Technol Assess Health Care. 2017;33(1):1-4.

59. Health technology assessment in Canada: improving the system and ensuring the patient voice is heard. Etobicoke, ON: Best Medicines Coalition; 2014. Available from: https://bestmedicinescoalition.org/wpcontent/uploads/2017/03/HealthTechnologyAssessment.pdf. Accessed October 15, 2017.

60. Public involvement programme annual report 2015. London: National Institute for Health and Care Excellence; 2015. Available from: https:// www.nice.org.uk/Media/Default/GetInvolved/Public\%20Involvement/ public_involvement_annual_report_2015.pdf. Accessed October 15, 2017.

61. Husereau D, Dempster W, Blanchard A, Chambers J. Evolution of drug reimbursement in Canada: the pan-Canadian Pharmaceutical Alliance for new drugs. Value Health. 2014;17(8):888-894.

62. Rawson NSB. Pan-Canadian Pharmaceutical Alliance: another hurdle for Canadian patients to access new drugs? Canadian Health Policy. Toronto: Canadian Health Policy Institute; 2016. Available from: http:// www.canadianhealthpolicy.com/products/pan-canadian-pharmaceutical-alliance--another-hurdle-for-canadian-patients-to-access-newdrugs-.html. Accessed October 15, 2017.

63. Grégoire JP, MacNeil P, Skilton K, et al. Inter-provincial variation in government drug formularies. Can J Public Health. 2001;92(4):307-312.

64. West R, Borden EK, Collet JP, Rawson NSB, Tonks RS. Need for an improved submission process for listing drugs for reimbursement in Canadian provinces. Can J Clin Pharmacol. 2003;10(4):207-210.

65. Menon D, Stafinski T, Stuart G. Access to drugs for cancer. Can J Public Health. 2005;96(6):454-458.

66. Ungar WJ, Witkos M. Public drug plan coverage for children across Canada: a portrait of too many colours. Healthc Policy. 2005;1(1): $100-122$.

67. Gamble JM, Weir DL, Johnson JA, Eurich DT. Analysis of drug coverage before and after the implementation of the Common Drug Review. CMAJ. 2011;183(17):E1259-1266.

68. Gill SS, Gupta N, Bell CM, Rochon PA, Austin PC, Laupacis A. The timing of drug funding announcements relative to elections: a case study involving dementia medications. PLoS One. 2013;8(2):e56921. 
69. Kerr A, Todd C, Ulyate K, Hebborn A. A comparison of international health technology assessment systems - does the perfect system exist? Dee Why, NSW: Roche Products (Australia); 2014. Available from: https://www.ispor.org/research_pdfs/48/pdffiles/PHP221.pdf. Accessed October 15, 2017.

70. NP view: new bill falls short of Liberals' promises for increased transparency. National Post. Toronto: National Post; 2017 Sep 29. Available from: http://nationalpost.com/opinion/np-view-trudeau-promised-tomake-government-more-transparent-their-new-bill-does-the-opposite. Accessed October 15, 2017.

71. Right to know. Gatineau, Quebec: Office of the Information Commissioner of Canada; 2014. Available from: http://www.oic-ci.gc.ca/ rtk-dai-eng/historique-history.aspx. Accessed October 15, 2017.
72. Openness. Transparency. Fairness. Making government work for Canadians. Ottawa: Liberal Party of Canada; 2017. Available from: https://www.liberal.ca/openness-and-transparency. Accessed October $15,2017$.

73. Trudeau J. Open and accountable government. Ottawa: Her Majesty the Queen in Right of Canada; 2015. Available from: http://pm.gc. ca/sites/pm/files/docs/OAG_2015_English.pdf. Accessed October 15, 2017.

74. Starr K. Justin Trudeau hints at national child-care plan tied to income. CBC/Radio-Canada. Ottawa: CBC/Radio-Canada; 2015 May 9. Available from: http://www.cbc.ca/news/politics/justin-trudeau-hints-atnational-child-care-plan-tied-to-income-1.3065235. Accessed October $15,2017$.

\section{ClinicoEconomics and Outcomes Research}

\section{Publish your work in this journal}

ClinicoEconomics and Outcomes Research is an international, peerreviewed open-access journal focusing on health technology assessment, pharmacoeconomics and outcomes research in the areas of diagnosis, medical devices, and clinical, surgical and pharmacological intervention. The economic impact of health policy and health systems
Submit your manuscript here: https://www.dovepress.com/clinicoeconomics-and-outcomes-research-jounf

organization also constitute important areas of coverage. The manuscript management system is completely online and includes a very quick and fair peer-review system, which is all easy to use. Visit http://www.dovepress.com/testimonials.php to read real quotes from published authors. 